\title{
A family with spondyloepimetaphyseal dwarfism: a 'new' dysplasia or Kniest disease with autosomal recessive inheritance?
}

\author{
T I FARAG*, SA AL-AWADI*, M C HUNT $\dagger$, S SATYANATH \\ M ZAHRAN\&, R USHA $\dagger$, AND R UMA $\dagger$ \\ From ${ }^{*}$ the Kuwait Medical Genetics Centre; $†$ Paediatric Department, Al-Jahra Hospital; and $¥$ Radiological \\ Department Al-Sabah, §Al-Jahra Hospital, Kuwait.
}

SUMmaRY We present an Arab family with some features of Kniest disease. The proband was a six year old boy with rhizomelic short limbed dwarfism, 'dish-like' facies, cleft palate, deafness, and camptodactyly. Most radiological changes were compatible with Kniest disease. Two younger sibs, similarly affected, had died at a few months old, and the pedigree shows strong evidence of autosomal recessive inheritance, unlike previously reported cases of Kniest disease which have shown autosomal dominant inheritance.

There are many forms of dwarfism associated with spinal as well as epiphyseal and metaphyseal changes seen in radiographs. However, the most striking feature in this family was the enormous enlargement of the metaphyseal region of the long bones in infancy, which is one of the predominant radiological features of Kniest disease, first described by Kniest ${ }^{1}$ in 1952 , and subsequently discussed in relation to similar disorders by other authors. $^{2-5}$

\section{Case reports}

CASE 1

The proband (fig 1, III.5) was an intelligent boy born at term after a normal pregnancy and delivery. He had four normal sibs and two younger affected ones. His Syrian parents were phenotypically normal. He was referred to the Genetics Clinic because

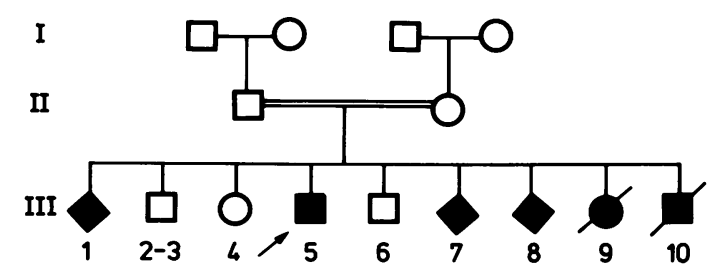

FIG 1 Family pedigree.

Received for publication 30 September 1986. Accepted for publication 6 October 1986. of disproportionate short stature diagnosed as either atypical achondroplasia, Crouzon syndrome, or Kniest disease. His height and weight were below the 3rd centile, with marked rhizomelic shortening in both upper and lower limbs (fig 2). He had a

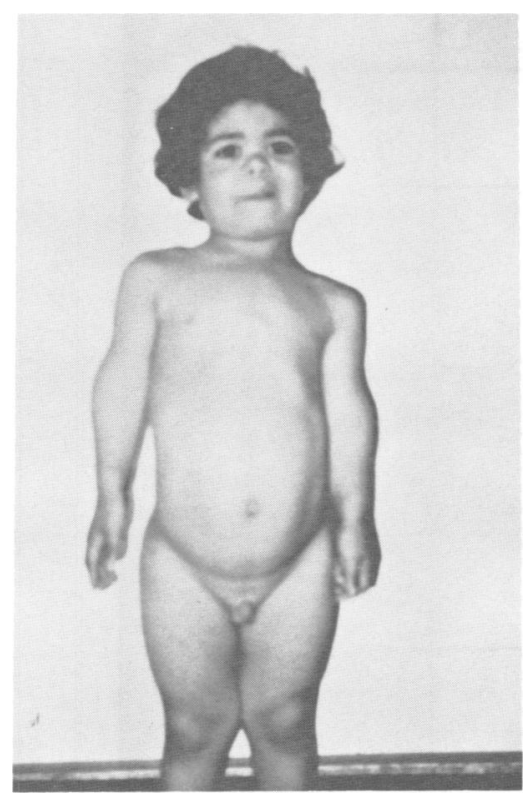

FIG 2 The proband (III.5) showing short limbs, particularly the proximal portion, and flattened face. 


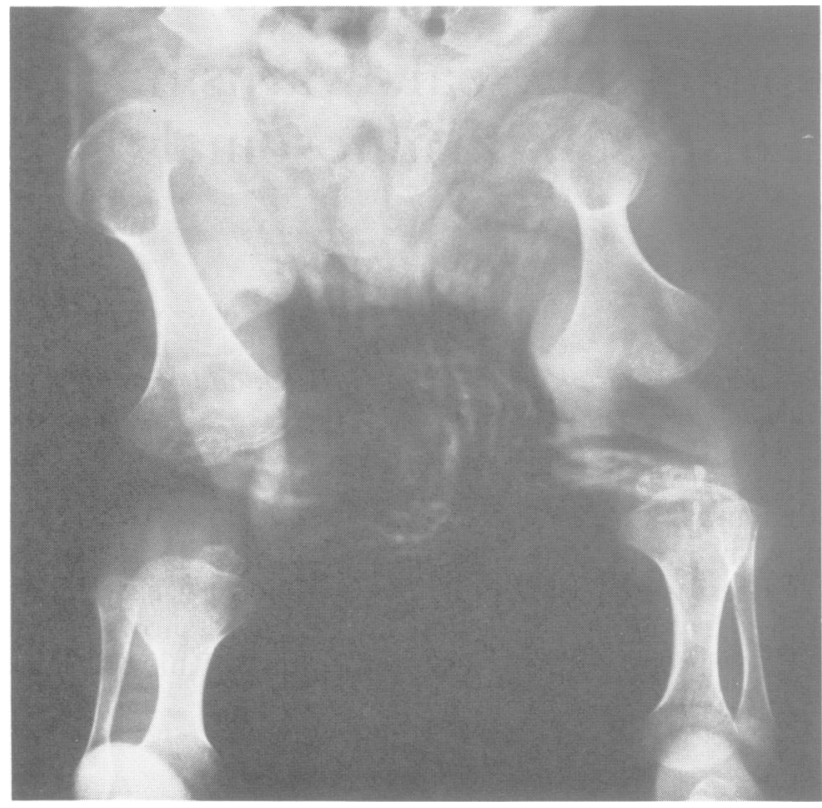

(a)

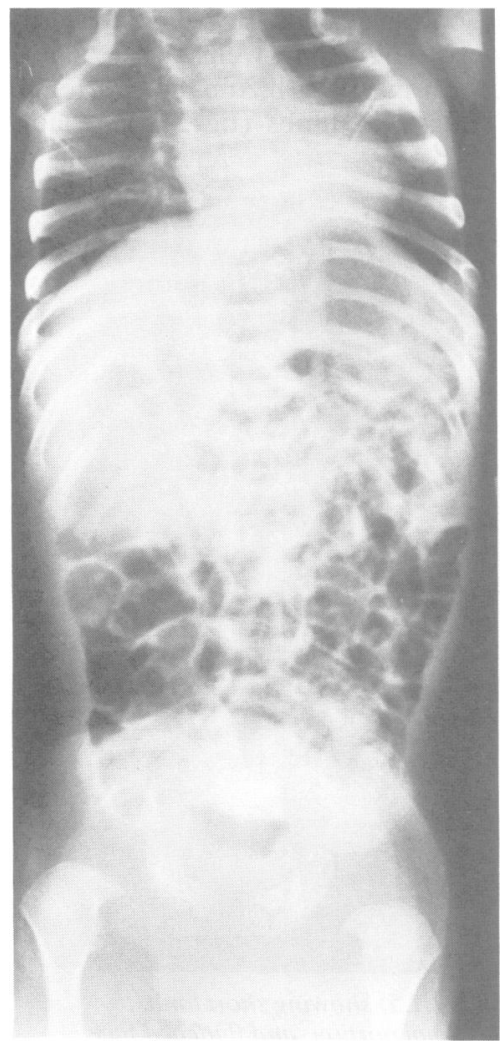
tion. (b)

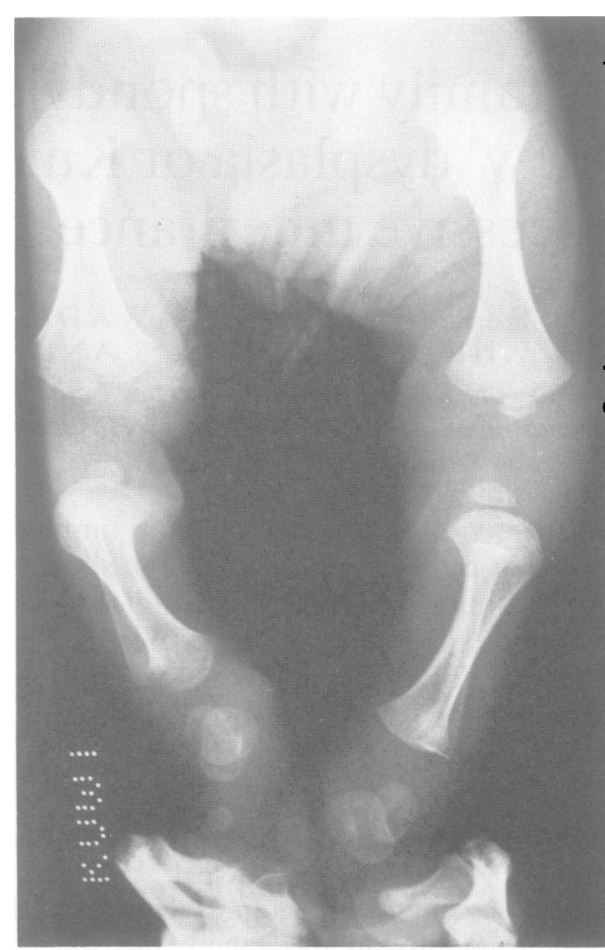

FIG 3 The dumb-bell shaped long bones of (a) patient III. 9 and (b) patient III.10 in the first few months of life.

'dish-like' facies with frontal bossing, hypertelorism? depressed nasal bridge, anteverted nostrils, a long़्? philtrum, very narrow external auditory meatus. bilateral moderate mixed hearing loss, a repaired cleft palate, and camptodactyly. The serum calcium phosphorus, magnesium, and alkaline phosphatase. were all normal. The child has been followed up fog three years, with no essential change in his condi

Clinical, radiological, and ophthalmologica assessment of the parents showed them to be phenotypically normal.

CASE 2

A younger sister (III.9) was delivered normally a term. She was first examined at two months of age $\omega_{\sigma}^{\omega}$ Her weight and height were below the 3rd centile and she had marked rhizomelic shortening with similar facial appearance to her brother, togethe with a posterior cleft palate and camptodactyly of

FIG 4 Narrow chest and mild platyspondyly seen in the early months. 


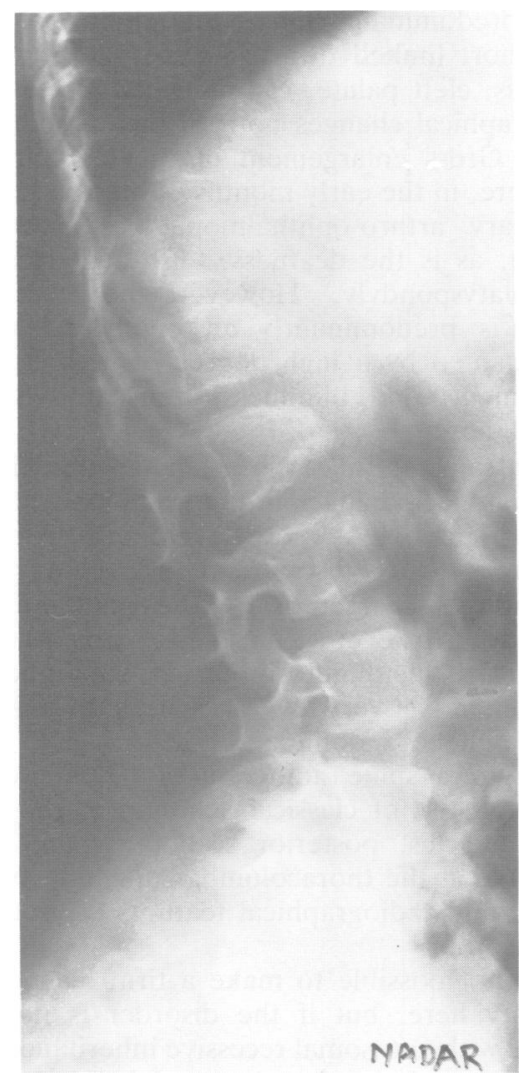

FIG 5 Platyspondyly is not marked in the lumbar region by the age of six years, but pedicles are short, with scalloping of the posterior border of the vertebral bodies, indicating spinal stenosis. the little finger. Failure to thrive and recurrent gastrointestinal and chest infections were major problems and she died outside Kuwait at four months of age after severe gastroenteritis.

\section{CASE 3}

A younger brother (III.10) was delivered by caesarean section for brow presentation and had a birth weight of $4010 \mathrm{~g}$, with Apgar scores 5 and 8 . He also had marked rhizomelic shortening, 'dish-like' facies, a posterior cleft palate, and camptodactyly of the little finger, but in addition he had micrognathia and glossoptosis. He too had recurrent chest infections and failure to thrive. Haematological, biochemical, and immunological tests were normal. He died at eight months of age after fulminating bronchopneumonia.

\section{RADIOLOGICAL FINDINGS}

The three patients described above all showed similar findings. The spine showed a lordosis in the cervicothoracic region instead of the normal kyphosis and only mild generalised platyspondyly with anterior wedging of the thoracolumbar vertebrae, together with posterior vertebral scalloping in the lumbar region. The long bones were all shortened with striking enlargement of the metaphyses and loss of bone moulding, particularly during the first year of life (figs 3 and 4). This was less marked in the six year old (figs $5,6,7,8$ ).

\section{Discussion}

The disorder appears to be of autosomal recessive

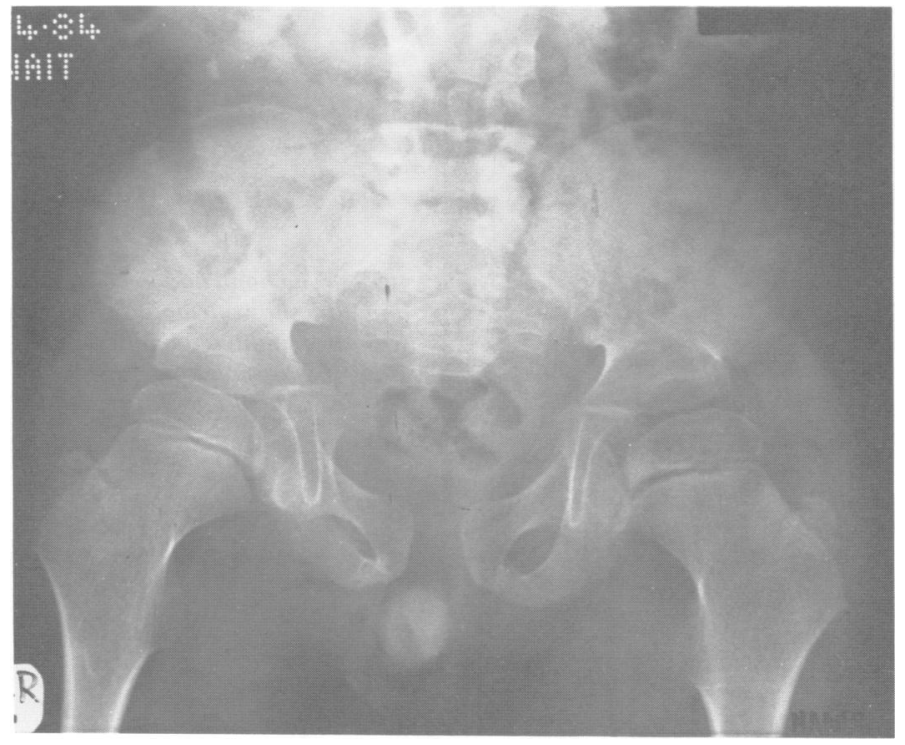

FIG 6 The pelvis is rather square and small, with narrow sciatic notches. The metaphyseal enlargement has now disappeared in the six year old proband, but the capital femoral epiphyses are large for this age. 
inheritance; parental consanguinity was not a known feature, but is nevertheless likely in a country such as Kuwait with a very high consanguinity rate $(54.3 \%)$, high average inbreeding coefficient $(\mathrm{F}=0 \cdot 0219)$, and large family size. ${ }^{6}$

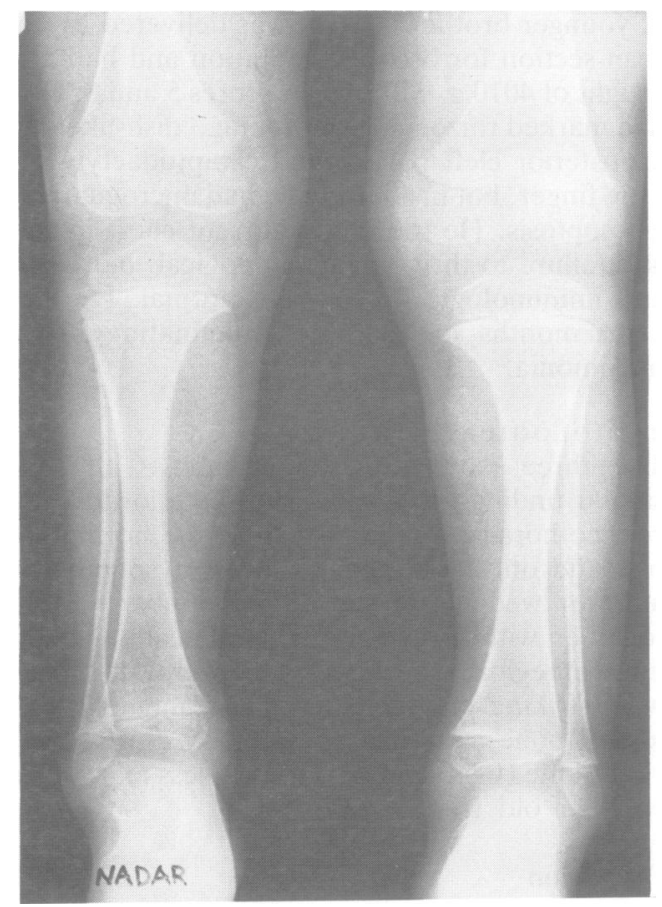

FIG 7 Some metaphyseal flaring persists around the knee and in the lower tibia, where there is also poor epiphyseal development.
The predominant clinical and radiological findings $\overrightarrow{\vec{s}}$ were short limbed dwarfism, characteristic facies, deafness, cleft palate, camptodactyly, and striking radiographical changes both in the spine and long $\frac{\bar{c}}{\bar{c}}$

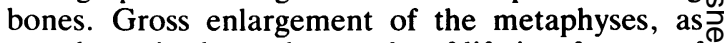
seen here, in the early months of life is a feature of $\stackrel{0}{0}$ hereditary arthro-ophthalmopathy (Stickler syn-œ drome), as is the deafness, 'dish-like' facies, and $\vec{\circ}$ mild platyspondyly. ${ }^{7}$ However, the Stickler syn- $-{ }_{-}$ drome is predominantly an epiphyseal disorder $\vec{\omega}$ accompanied by a high degree of myopia, retinal $\stackrel{\circ}{=}$ detachment, and blindness, none of which was present here.

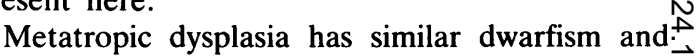
radiographical changes in the long bones, but here $\vec{O}$ the platyspondyly is more severe with 'paper thin' vertebrae. ${ }^{8}$ Kniest disease is the more likely diagnosis, with its characteristic facies and mild platyspondyly. However, Kniest disease is usually de- $\overrightarrow{0}$ scribed as being of autosomal dominant inheritance, although in fact very few cases are known and thereo could well be a dominant type.

The lateral spine radiograph of the older child has characteristics of classical achondroplasia, with itso0 short pedicles, posterior scalloping, and wedged vertebrae at the thoracolumbar junction, but othero clinical and radiographical features do not suggest this disorder.

It is not possible to make a firm diagnosis withă certainty here, but if the disorder is not Kniesto disease with autosomal recessive inheritance, then it is likely to be a 'new' spondyloepimetaphyseaB dysplasia.

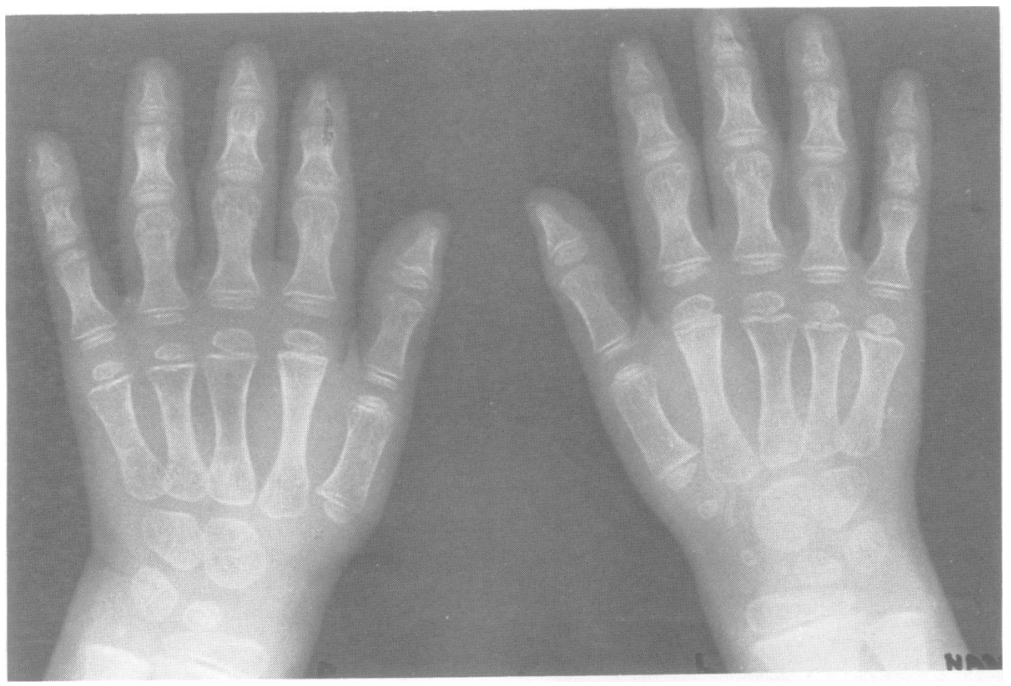

FIG 8 The hand and lower radius and ulna show metaphyseal flaring with shortening of all long bones. Bone maturation is average for a six year old child. 
We thank Dr Ruth Wynne-Davies for her help and Drs Arafa, H Abdel Wahab, S Abdel Razak, S Mady, and M Y El-Khalifa for their help during comprehensive assessment of the patients and their parents. We also thank Mrs Sarala Ramachandran for secretarial assistance.

\section{References}

1 Kniest W. Zur Abgrenzung der Dysostosis enchondralis von der Chondrodystrophic. Z Kinderheilkd 1952;70:633.

2 Maroteaux P, Spranger J. La maladie de Kniest. Arch Fr Pediatr 1973;30:735.

${ }^{3}$ Kozlowski K, Barylak A, Kobielowa Z. Kniest syndrome. Report of two cases. Australas Radiol 1977;21:60.

4 Rimoin DL, Siggers DC, Lachman RS, Silberberg R. Metatro- pic dwarfism, the Kniest syndrome and the pseudoachondroplastic dysplasias. Clin Orthop 1976;114:70.

5 Wynne-Davies R, Hall CM, Apley AG. Atlas of skeletal dysplasias. Edinburgh: Churchill-Livingstone, 1985.

- Al-Awadi SA, Moussa MA, Naguib KK, Farag TI, El-Khalifa MY, El-Dossary L. Consanguinity among the Kuwaiti population. Clin Genet 1985;27:483-6.

7 Winter RM, Baraitser M, Laurence KM, Donnai D, Hall CM. The Weissenbacher-Zweymuller, Stickler and Marshall syndromes. Further evidence for their identity. Am J Med Genet 1983;16:189.

${ }^{8}$ Jenkins P, Smith MB, McKinnel JS. Metatropic dwarfism. Br J Radiol 1970;43:561.

Correspondence and requests for reprints to $\mathrm{Dr} \mathrm{T} \mathrm{I}$ Farag, PO Box 31145, Sulibikhat 90802, Kuwait. 